\title{
O romance polifônico de Dostoiévski: questões de linguagem, dialogismo e gênero
}

\author{
Fernanda Taís Brignol Guimarães ' (UCS/UniRitter) \\ Adail Ubirajara Sobralii (UCPel/UFPEL)
}

\begin{abstract}
Resumo: Este estudo trata da categoria de romance polifônico, atribuída por Bakhtin para caracterizar a obra de Dostoiévski, em oposição ao romance monológico anterior a ele. Iniciamos por apresentar brevemente o contexto em que se desenvolveu o estudo de Bakhtin sobre a polifonia na obra de Dostoiévski. Em seguida discutimos as duas categorias do romance, criadas pelo filósofo russo, a saber: romance monológico e romance polifônico, e abordamos as especificidades do gênero romance, que fizeram com que Bakhtin tomasse esse gênero como objeto de suas investigações. Por fim, tratamos da polifonia caracterizada por Bakhtin como típica do romance dostoievskiano.
\end{abstract}

Palavras-chave: Bakhtin; Dialogismo; Romance Polifônico de Dostoiévski

\begin{abstract}
This study deals with the category of polyphonic novel used by Bakhtin to explain Dostoevsky's work, as opposed to the monological novel prior to it. We begin by briefly presenting the context in which Bakhtin's study about polyphony in Dostoevsky's work was developed. Soon after, we discuss the two categories of the novel, created by the Russian philosopher, namely: monological novel and polyphonic novel, and discuss the specificities of the genre novel, which made Bakhtin take this genre as an object of his investigations. Finally, we discuss polyphony defined by Bakhtin as typical of Dostoievskian novel.

Keywords: Bakhtin; Dialogism; Polyphonic novel of Dostoievsky
\end{abstract}




\section{O romance polifônico de Dostoiévski}

Uma só voz nada termina e nada resolve. Duas vozes são o mínimo de vida, o mínimo de existência.

Bakhtin (1981: 223)

Ao romance de Dostoiévski Bakhtin atribui o estatuto de espaço da verdadeira polifonia. "Problemas da poética de Dostoiévski e A cultura popular na Idade Média e no Renascimento: o contexto de Rabelais são obras que firmaram o nome de Mikhail Mikhailovich Bakhtin (1895-1975) no contexto das reflexões literárias contemporâneas" (BRAIT, 2013, pp. 45-46). A obra de Bakhtin, como se sabe, reúne um complexo pensamento que compõe sua filosofia da linguagem. Tratar de um aspecto ou de outro de forma isolada é algo praticamente impossível, já que a teoria dialógica da linguagem, de Bakhtin e o Círculo, abrange e entrelaça conceitos que complementam uns aos outros, tais como, em especial, dialogismo, polifonia, carnavalização, gêneros do discurso, entre outros. Falar de um deles fará suscitar, mesmo que de forma implícita, todos os outros. A análise de romances a que o filósofo russo se dedicou fez que sua teoria fosse aplicada primeiramente aos estudos literários, vindo mais tarde a integrar também os estudos linguísticos.

De acordo com Brait (2013), a primeira edição de Problemas da poética de Dostoiévski data de 1929, mesmo ano da prisão de Bakhtin. Apenas em 1961 Bakhtin decide publicar uma segunda edição do texto, que, em sua primeira versão (1929), fora alvo de fortes críticas por seu viés marxista e, o que é ainda mais grave, na visão de Brait, fora mal interpretada, suscitando uma leitura equivocada a respeito da polifonia. O texto reformulado destaca "a participação especial da aventura, da sátira menipeia, da concepção do espaço e da praça, da festa, do jogo, do conflito, assim como a concepção inovadora da posição do autor e do terceiro no diálogo" (BRAIT, 2013, p. 51). Em síntese, a análise de Bakhtin a respeito da obra de Dostoiévski revela:

(...) que ele destrói o antigo plano de representação do mundo, substituindo-o pelo caráter dialógico do autor que interroga, provoca, responde, jamais abafando a voz do outro. Muitos outros temas presentes nas narrativas dostoievskianas vão sendo registrados para futuro desenvolvimento: a ideia de fronteira, de limiar de consciências, do papel do capitalismo na criação da consciência solitária, da ampliação do conceito de consciência e sua natureza dialógica, a questão da voz, da 
ideologia e do homem, da confissão, do eu-para-si e do eu-para-o-outro, entre muitos outros (BRAIT, 2013, p. 51).

Bakhtin descreve a obra de Dostoiévski como a única capaz de abrigar a autêntica polifonia no sentido de que o autor se mostra como regente de uma multiplicidade de vozes e de consciências que não se misturam e que compartilham o mesmo estatuto, que não estão subordinadas ao autor, mas são postas por ele a dialogar entre si, quase como se o autor-criador estivesse em pé de igualdade. Dostoiévski, portanto, organiza no plano discursivo de seu romance um coro de vozes na interação de personagens-sujeito, donos de ideologias próprias, podendo até mesmo se apresentar como contrárias à ideologia do autor-criador da obra. Assim, Dostoiévski, assumindo o papel de regente desse coro, representa em sua obra "o homem no homem", conforme pontua Bakhtin,

A idéia (sic) enquanto objeto de representação ocupa posição imensa na obra dostoievskiana, porém não é ela a heroína dos seus romances. Seu herói é o homem, e o romancista, em suma, não representava a idéia no homem mas, segundo suas próprias palavras "o homem no homem". A idéia (sic) propriamente dita era para ele a pedra de toque para experimentar o homem no homem ou uma forma de localizá-lo ou, por último - e isto é o principal - o "médium", o meio no qual a consciência humana desabrocha em sua essência mais profunda (BAKHTIN, 1981, p. 25 [grifos no original]).

Cabe destacar que é da análise do romance de Dostoiévski que nasce a categoria de romance polifônico, que se opõe ao romance monológico, anterior a ele, em que tudo era dado a conhecer pelo autor da obra, aquilo que a teoria literária denomina autor onisciente. Enquanto o romance polifônico envolve uma multiplicidade de consciências, de personagens que dialogam entre si e com seu autor-criador, o romance monológico envolve uma só consciência - a consciência do autor - a que todas as demais consciências - das personagens - estão subordinadas. Bakhtin mostra a obra de Dostoiévski como um divisor de águas, que introduz uma fase mais evoluída do romance. Isso porque, no romance polifônico, a personagem deixa de ser um puro objeto do agir do autor-criador para assumir o estatuto de outro sujeito. Na próxima seção, aprofundamos a distinção bakhtiniana.

\section{As duas categorias do romance: o polifônico e o monológico}


A comunicação discursiva é parte de uma grande rede socioideológica. A língua, fora do âmbito do sistema abstrato da linguística tradicional, não é, segundo a teoria dialógica, neutra. Muito pelo contrário, ela reflete, refratando, diferentes valorações, crenças e posições dos sujeitos, que se inscrevem socialmente na e pela linguagem. É por meio da linguagem que o sujeito constrói sua identidade e se constitui como um eu no mundo frente a outros eus. Na verdade, a identidade vem da alteridade, ou, se se quiser, a subjetividade nasce da intersubjetividade, da interação entre subjetividades, do diálogo entre elas. Do mesmo modo, conforme Bakhtin, tudo na língua dialoga entre si, tudo faz parte de uma rede de interlocução que faz que a interação entre os sujeitos se dê mediante a produção de enunciados concretos que estão vinculados a uma grande cadeia do discurso, de cunho social e ideológico. O discurso, a língua em uso, portanto, se apresenta como um elo entre todos os enunciados, tanto os já realizados, como os que virão a realizar-se. Nas palavras de Bakhtin,

A orientação dialógica é naturalmente um fenômeno próprio a todo discurso. (...) Em todos os seus caminhos até o objeto, em todas as direções, o discurso se encontra com o discurso de outrem e não pode deixar de participar, com ele, de uma interação viva e tensa (BAKHTIN, 2014, p. 88).

Todo enunciado é, em consequência, dialógico, no sentido de que faz ecoar pelo menos duas vozes: a do locutor e a do interlocutor, o mínimo necessário para haver diálogo. Ainda que o interlocutor não esteja fisicamente presente, seu estatuto como é de parte integrante e inalienável do discurso. Na verdade, a escolha do gênero e dos meios linguísticos depende da endereçabilidade a um dado interlocutor, seja ele real ou presumido, típico. O interlocutor, assim, está sempre presente, e, mais do que isso, altera o agir do locutor.

Para Bakhtin, nos termos da definição de seu conceito de relações dialógicas, (mais tarde chamado de "dialogismo" por leitores do filósofo), todo elogio carrega uma crítica; toda recusa carrega uma aceitação; toda afirmação carrega uma negação. Porque tudo na língua está relacionado de forma responsiva, isto é, o discurso mostra-se sempre como uma resposta (no sentido de réplica) a outros discursos, e tudo que é dito mostra-se como um "já dito" e prevê antecipadamente outros discursos que surgirão após ele. A respeito disso, Bakhtin diz ainda que "O discurso nasce no diálogo como sua réplica viva, forma-se na mútua-orientação dialógica do discurso de outrem no interior do objeto. A 
concepção que o discurso tem de seu objeto é dialógica" (BAKHTIN, 2014, pp. 88-89). Assim, os objetos do mundo já são referenciados pelas enunciações como alvo de um embate de valorações; os signos nos chegam valorados, não com um sentido unívoco aceito por todos. As significações da língua são apropriadas pelos enunciados para criar sentido.

Diante disso, ao contrário do que se possa pensar, diálogo e dialogismo não são sinônimos. O diálogo envolve a interlocução entre dois sujeitos de forma explícita, ao passo que o dialogismo constitui todo e qualquer fenômeno de linguagem. Trata-se da configuração interna do discurso, que se encontra com o discurso de outrem e com ele concorda ou discorda, argumenta, critica, pontua etc. Nestes termos, por mais monológico que um texto possa parecer, ele sempre será dialógico. Ele sempre trará em sua superfície, além da voz do locutor, pelo menos outra voz, isto é, a voz do interlocutor, a quem esse texto se dirige, ainda que se possa afirmar que "um texto tende para o monologismo mais do que outro" (AMORIM, 2002, p. 12), ou, como diz Sobral (2006), há textos tendencialmente monológicos e textos tendencialmente dialógicos:

(...) todo discurso (e, mesmo toda palavra) é arena, lugar de confronto, de presença do outro, não se podendo pois conceber um discurso monológico no sentido de discurso que neutralize todas as vozes que não a daquele que enuncia (...) a concepção de outro do Círculo é complexa: o outro pode ser amigável, submisso, autoritário, inimigo etc., permanecendo em todos os casos constitutivo do eu, tal como este é, como se costuma dizer, "o outro do outro". Pode-se, não obstante, perceber nos discursos o que proponho denominar "tendência ao monológico" e "tendência ao dialógico", para dar conta dos graus de dialogismo "mostrado" a partir de seus dois extremos, naturalmente possíveis apenas em termos teóricos, mas não concretamente verificáveis - os discursos monológicos e dialógicos "puros" (SOBRAL, 2006, p. 74 [grifos no original]).

Mas se tudo na língua é dialógico, se todo discurso nasce do encontro com o discurso de outrem, então em que medida se sustenta a classificação de Bakhtin da obra de Dostoiévski como formada por romances polifônicos, em oposição ao romance monológico? Haveria então, antes de Dostoiévski, um romance monológico estrito? Certamente o autor não está falando do conteúdo estético que compõe o romance, uma vez que, como toda modalidade de expressão via linguagem, o romance é composto por uma rede de relações dialógicas, as quais, para Bakhtin, consistem em um

(...) fenômeno bem mais amplo do que as relações entre as réplicas do diálogo expresso composicionalmente - são um fenômeno quase universal, que penetra toda a linguagem humana e todas as relações e manifestações 
da vida humana, em suma, tudo o que tem sentido e importância. (BAKHTIN, 1981, p. 34).

Nas relações dialógicas, figura uma cadeia de enunciados interligados, no sentido de constituírem uma relação de diálogo com outros enunciados. Desse modo, o conteúdo linguístico mobilizado nos romances, assim como todo enunciado produzido em qualquer que seja a situação de uso da linguagem, mostra-se como uma resposta, uma objeção, uma reação, um argumento, uma concordância, etc. com outros enunciados já produzidos ou que virão a ser produzidos socialmente. Assim, quando Bakhtin estabelece a categoria de romance monológico, ele está se referindo à criação do romance como um monólogo, isto é, como um discurso que se mostra advindo de uma só consciência, como um único enunciado produzido pela consciência individual do autor, que tem em suas personagens figuras objetificadas de meros transmissores e divulgadores de suas ideias.

Lembremos que a enunciação pressupõe sempre a relação do enunciador com seu destinatário, que é parte constitutiva da superfície discursiva, no sentido de que determina a organização do conteúdo no plano do discurso. E sendo a enunciação única e irrepetível, nos termos de Bakhtin, um discurso nunca será igual ao outro. A organização do conteúdo no plano discursivo depende da relação entre locutor e interlocutor que se estabelece em dada enunciação. Se se alteram os participantes da enunciação, também irá se alterar o discurso como um todo, se estará diante de outra enunciação, a que o autor criador - a posição valorativa, estético-formal engendradora do discurso - dará forma.

Como esclarece Bezerra (2013, p. 192), "O modelo monológico não admite a existência da consciência responsiva e isônoma do outro; para ele não existe o 'eu' isônomo do outro o 'tu'". O romance anterior a Dostoiévski, dessa forma, mostra-se como um discurso uno, fechado, acabado, em que o autor tem pleno domínio sobre o destino de suas personagens, as quais dão a conhecer dentro da obra as ideias de uma única consciência, a consciência do autor. Sobre a categoria de romance monológico, Bezerra esclarece ainda que:

Segundo Bakhtin, no monologismo o autor concentra em si mesmo todo o processo de criação, é o único centro irradiador da consciência, das vozes, das imagens e pontos de vista do romance: "coisifica" tudo, tudo é objeto mudo desse centro irradiador, o modelo monológico não admite a existência da consciência responsiva e isônoma do outro; para ele não existe o "eu" isônomo do outro, o "tu". O outro nunca é outra consciência, é mero objeto da consciência de um "eu" que tudo enforma e comanda. O 
monólogo é algo concluído e surdo à resposta do outro, não reconhece nela força decisória. Descarta o outro como entidade viva, falante e veiculadora das múltiplas facetas da realidade social e, assim procedendo, coisifica em certa medida toda a realidade e cria um modelo monológico de um universo mudo, inerte. Pretende ser a última palavra. (...) Para Bakhtin, no universo monológico as personagens (...) são objeto do discurso do autor, que não as vê como sujeitos, como consciências capazes de falar e responder por si mesmas, mas como coisas, como matéria muda que se esgota e se imobiliza no acabamento definitivo que ele lhe dá (BEZERRA, 2013, p. 192 [grifos no original]).

Apresentado por Bakhtin como o oposto do romance monológico, o romance polifônico de Dostoiévski torna o dialogismo presente mediante a multiplicidade de consciências independentes das personagens, que se mostram como "eus" independentes do "eu" do autor. As personagens de Dostoiévski possuem valores ideológicos que independem dos valores do autor, elas o contestam, dialogam com ele em pé de igualdade, podendo até mesmo se rebelar contra ele, seu autor-criador, já que consistem em "personagens-indivíduos", apresentando-se assim como sujeitos do discurso e não apenas como objeto da consciência do autor (cf. BEZERRA, 2013, pp. 198-199). Em consequência, Dostoiévski não determina as ações das personagens, as quais têm vida própria e poder de decisão sobre si mesmas, mas se apresenta como maestro das múltiplas vozes e consciências sociais de suas personagens, que debatem ideias e pontos de vista sobre o mundo, o que torna seus rumos imprevisíveis mesmo para seu autor.

Ainda sobre as duas modalidades de romance estabelecidas por Bakhtin, Bezerra aponta que "À categoria de monológico estão associados os conceitos de monologismo, autoritarismo, acabamento [e] à categoria de polifônico, os conceitos de realidade em formação, inconclusibilidade, não acabamento, dialogismo, polifonia" (BEZERRA, 2013, p. 191). Em contrapartida,

O dialogismo e a polifonia estão vinculados à natureza ampla e multifacetada do universo romanesco, ao seu povoamento por um grande número de personagens, à capacidade do romancista para recriar a riqueza dos seres e caracteres humanos traduzida na multiplicidade de vozes da vida social, cultural e ideológica apresentada. (BEZERRA, 2013, pp. 191192).

Para Bezerra, o acabamento, autoritário, indiscutível, que apaga os universos de cada personagem e as sujeita ao autor como mostra Bakhtin, não é uma característica do romance dostoievskiano, que apresenta as personagens como sujeitos independentes que travam diálogos entre si e com o autor. Quanto ao autoritarismo, pode-se dizer que, no 
romance polifônico de Dostoiévski, não há uma única verdade, indiscutível, posta como único caminho a ser seguido pelas personagens, mas sim uma complexa multiplicidade de vozes e pontos de vista em constante embate valorativo, o que põe em um mesmo plano discursivo conteúdos opostos e contraditórios, travando relações dialógicas por meio de uma multiplicidade complexa de consciências que não se confundem e tem atribuído a si um mesmo estatuto. Esse proceder corrobora o não acabamento do discurso de Dostoiévski, já que não há um caminho único para o desfecho final, sobre o qual o autor da obra monológica daria a última palavra. Não há na obra de Dostoiévski a última palavra, mas a inconclusibilidade, o embate de palavras.

\section{Análise do romance como campo de investigação para a Teoria Dialógica}

Bakhtin, em sua busca por explicar os fenômenos da linguagem, volta-se para a análise do romance por ser este um campo frutífero de investigação da complexa rede de relações dialógicas que compõe a interação humana. No universo romanesco estão representadas réplicas de todo tipo de interação, situadas em diferentes recortes espaçostemporais. As narrativas romanescas contemplam a réplica de uma diversidade infinita de gêneros orais e escritos: a conversa cotidiana, as manifestações religiosas, as manifestações em praça pública, a escrita de cartas, tratados, testamentos, testemunhos, as ordens militares etc. Assim, envolvem a participação de sujeitos de todas as classes sociais e o uso de uma diversidade de recursos de linguagem: ironia, paródia, sátira, alegoria, sarcasmo, linguagem carnavalizada, entre outros.

Diante disso, o romance constitui-se como um gênero inacabado, em formação. "A inconclusibilidade e o não acabamento decorrem da condição do romance como um gênero em formação, sujeito a novas mudanças, cujas personagens são sempre representadas em um processo de evolução que nunca se conclui" (BEZERRA, 2013, P. 191). Sobre esse não acabamento do romance, Bezerra destaca ainda que

$\mathrm{Na}$ ótica da polifonia, as personagens que povoam o universo romanesco estão em permanente evolução. O dialogismo e a polifonia estão vinculadas à natureza ampla e multifacetada do universo romanesco, ao seu povoamento por um grande número de personagens, à capacidade do romancista para recriar a riqueza dos seres e caracteres humanos traduzida na multiplicidade de vozes da vida social, cultural e ideológica representada (BEZERRA, 2013, pp. 191-192). 
Logo, são representadas pelo romancista diferentes enunciações, envoltas de crenças e valores, situadas em contextos sócio-histórico-culturais específicos e envolvendo interlocutores específicos.

É importante destacar que "Bakhtin distingue o autor pessoa (isto é, o escritor, o artista, a pessoa física) do autor criador (isto é, a função estético-formal engendradora da obra)." (FARACO, 2013, p. 105). Nesse sentido, quando é dito que as personagens de Dostoiévski dialogam com ele em pé de igualdade, não é ao autor pessoa que se está referindo, ou seja, a pessoa física de Dostoiévski, mas sim, ao autor criador, que se configura como uma "posição estético-formal cuja característica básica está em materializar uma certa relação axiológica com o herói e seu mundo (...)" (FARACO, 2013, p. 106). O autor criador faz parte do todo artístico, ele está presente na superfície discursiva da obra. Bakhtin o define como uma posição axiológica, que organiza a matéria verbal de acordo com determinada posição valorativa a respeito do herói. Conforme a definição de Faraco, o autor criador consiste, portanto, em

(...) um constituinte do objeto estético (elemento imanente ao todo artístico) - mais precisamente, aquele constituinte que dá forma ao objeto estético, o pivô que sustenta a unidade arquitetônica e composicional do todo esteticamente consumado. (FARACO, 2013, pp. 105-106).

A partir de dada posição valorativa com relação ao herói e seu mundo, o autor criador organiza as ações das personagens no plano discursivo da obra estética. Essa posição valorativa diz respeito ao modo como o autor criador vê suas personagens, podendo por elas demonstrar simpatia ou antipatia, podendo com elas comover-se ou alegrar-se, por exemplo; e, a partir do modo como ele se relaciona com elas (as personagens), é que ele irá dar forma ao discurso, construir a arquitetônica da obra, que, por conseguinte, determinará a forma composicional, a materialidade discursiva do todo estético. "É esse posicionamento valorativo que dá ao autor criador o princípio regente para construir o todo. É a partir dele que se criarão o herói e o seu mundo, isto é, se dará forma ao conteúdo" (FARACO, 2013, p. 106).

Em resumo, o autor-criador não se confunde com o indivíduo-autor, e é o autorcriador que constitui o autor-indivíduo como tal na própria obra (como o mostra, por exemplo, BRAIT, 1999). O autor-criador realiza essa inserção do autor-indivíduo 
por meio da forma e do material, em interação com o herói e com o ouvinte. $O$ autor, e aqui falamos do autor em geral, em vez do literário tout court, se é facilmente identificável como "imagem-objeto", não é parte da intenção nem do projeto do locutor; esse autor concreto não é o criador da palavra nem do discurso "enquanto autor de seu próprio enunciado" (BAKHTIN, 1997, p. 336). Logo, a existência concreta do autor [sua pessoa física] só é pertinente enquanto incorporada ao autor do discurso, ao ator que dá forma, que molda o material textual (SOBRAL, 2012, p. 132).

\section{A polifonia por excelência no romance de Dostoiévski}

Bakhtin aponta o romance de Dostoiévski como o único capaz de abrigar a "autêntica" polifonia, que para o filósofo russo, não reside apenas no fato de Dostoiévski ter desafiado o cânone literário da época ao fazer dialogar em seus textos uma diversidade de realidades sociais, fazendo emergir conteúdos contraditórios. Com relação à diversidade de conteúdos contraditórios postos em um mesmo plano discursivo por Dostoiévski, Bakhtin, ao apresentar sua versão, contesta a visão de Grossman, por considerá-la insuficiente para descrever as peculiaridades do romance dostoievskiano. Vejamos:

Para Grossman, a peculiaridade fundamental da poética de Dostoiévski reside na violação da unidade orgânica do material, que requer um cânon especial, na unificação dos elementos mais heterogêneos e mais incompatíveis da unidade da construção do romance, na violação do tecido uno e integral da narrativa. "É esse - diz ele - o príncipio fundamental da composição do seu romance: subordinar os elementos diametralmente opostos da narrativa à unidade do plano filosófico e ao movimento em turbilhão de acontecimentos. Combinar numa criação artística confissões filosóficas com incidentes criminais, incluir o drama religioso na fábula da estória vulgar, conduzir, através de todas as peripécias da narrativa de aventura, às revelações de um novo mistério (...). Contrariando as antigas tradições da estética, que exigia correspondência entre o material e a elaboração e pressupunha unidade e, em todo caso, homogeneidade e afinidade entre os elementos construtivos de uma dada criação artística, Dostoiévski coaduna os contrários. Lança um desafio decidido ao cânon fundamental da teoria da arte. Sua tarefa é superar a maior dificuldade para o artista: criar de materiais heterogêneos, heterovalentes e profundamente estranhos uma obra de arte una e integral. (...)" (BAKHTIN, 1981, pp. 9-10).

Embora reconheça na visão de Grossman "uma excelente caracterização

descritiva das peculiaridades do gênero e da composição dos romances de Dostoiévski", 
Bakhtin rebate a visão do autor afirmando que essas explicações se mostram insuficientes. Ele argumenta que:

Em realidade, o movimento em turbilhão dos acontecimentos, por mais potente que fosse, e a unidade do plano filosófico, por mais profundo que fosse, dificilmente seriam suficientes para a tarefa sumamente complexa e extremamente contraditória formulada com tanta argúcia e evidência por Grossman. Quanto ao movimento em turbilhão, qualquer novela cinematográfica vulgar pode competir com Dostoiévski. Em relação à unidade do plano filosófico, este por si só não pode servir de fundamento último da unidade artística (BAKHTIN, 1981, p. 10).

O que diferencia o romance de Dostoiévski dos romances anteriores a ele, na visão de Bakhtin, não é a diversidade de conteúdos opostos e contraditórios presentes em um mesmo plano discursivo, mas sim a maneira como o autor organiza esses conteúdos, de forma a fazer que coexistam simultaneamente em termos de diferentes ideias advindas de diferentes consciências de personagens-sujeito. Se todos esses conteúdos opostos presentes na obra de Dostoiéviski partissem de uma só consciência, a consciência do autor, o romance dostoieviskiano nada teria de peculiar, que assim, conforme pontua Bakhtin a respeito do movimento em turbilhão de que fala Grossman, "qualquer novela cinematográfica vulgar pode competir com Dostoiévski".

Em sua busca por experimentar o homem no homem, através da discussão das ideias, Dostoiévski apresenta um discurso que sempre se instaura no plano da simultaneidade de acontecimentos; suas personagens interagem num recorte definido de tempo, de forma a refletirem sobre temas do presente, ou que tenham ainda consequências sobre suas ações no momento presente. Dessa forma, essas personagens não trazem uma história passada, uma biografia da qual mantenham lembranças, a não ser que essas lembranças possuam alguma relação com acontecimentos vivenciados no momento presente. $E$, justamente por acontecer sempre no presente, na simultaneidade de fatos e acontecimentos, é que o romance de Dostoiévski não se dá de forma acabada, isto é, os rumos e caminhos trilhados por suas personagens não estão pré-definidos pelo autor, que não conhece seus destinos finais. "Cada atitude da personagem está inteiramente no presente e neste sentido não é predeterminada; o autor a concebe e representa como livre." (BAKHTIN, 1981, p. 23).

Com relação à simultaneidade de eventos presente na narrativa de Dostoiévski, Bakhtin diz ainda que: 
O extraordinário dom artístico de ver tudo em coexistência e interação (...) aguçava-lhe ao extremo a percepção na ótica de um dado momento e permitia ver coisas múltiplas e diversas onde outros viam coisas únicas e semelhantes. Onde outros viam apenas uma idéia ele conseguia tatear e encontrar duas idéias, um desdobramento; onde outros viam uma qualidade, ele descobria a existência de outra qualidade, oposta. Tudo o que parecia simples em seu mundo se tornava complexo e multicomposto. Em cada voz ele conseguia ouvir duas vozes em discussão, em cada expressão via uma fratura e a prontidão para se converter em outra expressão oposta; em cada gesto captava a segurança e a insegurança simultaneamente; percebia a profunda ambivalência e plurivalência de cada fenômeno. Mas essas contradições e esses desdobramentos não se tornaram dialéticos, não foram postos em movimento numa via temporal, numa série em formação mas se desenvolveram em um plano como contíguos e contrários, como harmonia eterna de vozes imiscíveis ou como discussão interminável e insolúvel entre elas. (BAKHTIN, 1981, p. 24)

Nestes termos, na análise de Bakhtin, o fenômeno da polifonia atribuído ao romance dostoievskiano não vem de conceitos prévios, mas nasce da própria análise das relações dialógicas presentes na obra, que caracterizam a polifonia através da multiplicidade de vozes sociais e da autoconsciência dada às personagens. Nas palavras de Bakhtin:

Em Dostoiévski a consciência nunca se basta por si mesma, mas está em tensa relação com outra consciência. Cada emoção, cada idéia da personagem é internamente dialógica, tem coloração polêmica, é plena de combatitividade e está aberta à inspiração de outras; em todo caso, não se concentra simplesmente em seu objeto mas é acompanhada de uma eterna atenção em outro homem. Podemos dizer que Dostoiévski apresenta em forma artística uma espécie de sociologia das consciências (...) (BAKHTIN, 1981, pp. 25-26).

Aí está posto o que Bakhtin quer dizer quando contrapõe o romance polifônico de Dostoiévski ao romance monológico. Quando fala de romance monológico, está se referindo ao discurso advindo de uma única consciência, a do autor da obra estética, a qual é representada como um monólogo e não ao conteúdo discursivo veiculado na obra, que do ponto de vista do dialogismo, mostra-se como parte da cadeia dialógica do fenômeno linguístico como um todo complexo, o qual emerge em dada sociedade organizada e mantém-se sempre em relação dialógica com outros discursos que o circundam. Como foi visto, o romance de Dostoiévski caminha em sentido oposto ao monologismo, já que suas personagens se mostram como sujeitos discursivos que não estão subordinados à ideologia do autor. 


\section{Referências Bibliográficas}

AMORIM, M. Vozes e silêncio no texto de pesquisa em ciências humanas. Cadernos de Pesquisa, n. 116, p. 7-19, julho/ 2002.

BAKHTIN, M. Problemas da poética de Dostoiévski. Tradução de Paulo Bezerra. Rio de Janeiro: Forense-Universitária, 1981.

Questões de literatura e de estética: a teoria do romance. Tradução de Aurora Fornoni

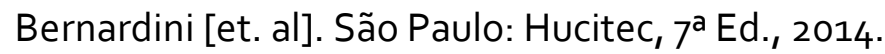

BRAIT, B. Problemas da Poética de Dostoiévski e estudos da linguagem. In: BRAIT, B. (Org.). Bakhtin, dialogismo e polifonia. São Paulo: Contexto $1^{\mathrm{a}}$ Ed., $2^{\mathrm{a}}$ reimpressão, 2013.

. Mikhail Bakhtin: O Discurso na Vida e o Discurso na Arte. In: DIETZSCH, M. J. M., Espaços da Linguagem na Educação. São Paulo: Humanitas, 1999, p. 11-39.

BEZERRA, P. Polifonia. In: BRAIT, B. (Org.). Bakhtin: conceitos-chave. São Paulo: Contexto $5^{\text {a }}$ Ed., $1^{\text {a }}$ reimpressão, 2013.

FARACO, C. A. Autor e Autoria. In: BRAIT, B. (Org.). Bakhtin: conceitos-chave. São Paulo: Contexto $5^{\text {a }}$ Ed., $1^{\text {a }}$ reimpressão, 2013.

SOBRAL, A. A concepção de autoria do "Círculo Bakhtin, Medvedev, Voloshinov": confrontos e definições. In: Macabéa - Revista Eletrônica do Netlli | V.1., N.2., De. 2012, p. $123-142$.

. Elementos sobre a formação de Gêneros discursivos: A fase "parasitária" de uma Vertente do gênero de auto-ajuda. 2006. 325 f. Tese (Doutorado em Linguística) Programa de Estudos Pós-Graduados em Linguística Aplicada e Estudos da Linguagem, Pontifícia Universidade Católica de São Paulo - PUC, São Paulo, 2006.

\footnotetext{
' Doutoranda pelo Programa de Pós-Graduação em Letras Associação Ampla UCS/UniRitter. Membro do Laboratório de Estudos Avançados de Linguagens - LEAL/UCPEL. CAPES/PROSUC.

E-mail: fernandabage@hotmail.com

ii Doutor em Linguística Aplicada e Estudos da Linguagem. Tradutor. Professor do Programa de Pósgraduação em Letras da Universidade Católica de Pelotas - UCPel e da Universidade Federal de Pelotas UFPEL. Coordenador do Laboratório de Estudos Avançados de Linguagens - LEAL/UCPel.

E-mail: adail.sobral@gmail.com
} 